\title{
Patient-specific statistical shape modeling for optimal spinal sagittal alignment in lumbar spinal fusion
}

\author{
Pascal R. Furrer ${ }^{1} \cdot$ Sebastiano Caprara $^{2} \cdot$ Florian Wanivenhaus $^{1} \cdot$ Marco D. Burkhard $^{1} \cdot$ Marco Senteler $^{2}$. \\ Mazda Farshad ${ }^{1}$
}

Received: 20 June 2020 / Revised: 22 March 2021 / Accepted: 18 April 2021 / Published online: 2 May 2021

(c) The Author(s) 2021

\begin{abstract}
Purpose The present study compared patients developing ASD after L4/5 spinal fusion with a control group using a patientspecific statistical shape model (SSM) to find alignment-differences between the groups.

Methods This study included patients who had undergone spinal fusion at L4/5 and either remained asymptomatic (control group; $n=25$, follow-up of $>4$ years) or required revision surgery for epifusional ASD ( $n=22)$. Landmarks on preoperative and postoperative lateral radiographs were annotated, and the optimal spinal sagittal alignment was calculated for each patient. The two-dimensional distance from the SSM-calculated optimum to the actual positions before and after fusion surgery was compared.

Results Postoperatively, the additive mean distance from the SSM-calculated optimum was $86.8 \mathrm{~mm}$ in the ASD group and $67.7 \mathrm{~mm}$ in the control group $(p=0.119)$. Greater differences were observed between the groups with a larger distance to the ideal in patients with ASD at more cranial levels. Significant difference between the groups was seen postoperatively in the vertical distance of the operated segment L4. The patients with ASD $(5.69 \pm 3.0 \mathrm{~mm})$ had a significant greater distance from the SSM as the control group $(3.58 \pm 3.5 \mathrm{~mm}, p=0.034)$.

Conclusion Patients with ASD requiring revision after lumbar spinal fusion have greater differences from the optimal spinal sagittal alignment as an asymptomatic control group calculated by patient-specific statistical shape modeling. Further research might help to understand the value of SSM, in conjunction with already established indexes, for preoperative planning with the aim of reducing the risk of ASD.

Level of evidence I Diagnostic: individual cross-sectional studies with consistently applied reference standard and blinding
\end{abstract}

Keywords Adjacent segment disease $\cdot$ ASD $\cdot$ Statistical shape model $\cdot$ Spinopelvic alignment $\cdot$ Preoperative planning

\section{Introduction}

Spinal fusion surgery is a commonly performed treatment with a broad spectrum of indications [1, 2]. Spinal fusion leads to a redistribution of forces throughout the spine, and the vertebral segments adjacent to the fusion must adapt to the rigid fixation beneath with compensatory increases in motion, intradiscal pressure, and force loading

Mazda Farshad

Mazda.farshad@balgrist.ch

1 Department of Orthopedic Surgery, Balgrist University Hospital, University of Zurich, Forchstrasse 340, 8008 Zurich, Switzerland

2 Institute for Biomechanics, Swiss Federal Institute of Technology (ETH), Zürich, Switzerland on facet joints [3-5]. Adjacent segment disease (ASD) is a broad term describing the condition that develops when the adjacent segment fails to adapt to these biomechanical redistributions and decompensates. Manifestations of ASD include adjacent disc degeneration and herniation, spinal stenosis, proximal junctional kyphosis, and adjacent vertebral compression fracture [6]. Several risk factors are associated with the occurrence of ASD, including age, female sex, obesity, osteoporosis, prior degenerative changes in the adjacent segment, and sagittal misalignment; among these, the surgeon may have a direct impact on sagittal misalignment [7-11]. Sagittal imbalance, most commonly measured by the pelvic incidence-lumbar lordosis mismatch $(\Delta \mathrm{PI}-\mathrm{LL})$ and sagittal vertical axis, has been associated with poor health-related quality of life and increased disability [12-14]. Failure to restore lumbar lordosis leads 
to increased force loadings at adjacent segments and may trigger ASD [11, 15-17]. Thus, patient-specific planning to optimally balance the delicate relationship between the pelvic anatomy and lumbar alignment is of paramount importance to achieve optimal long-term outcomes.

Computerized preoperative planning tools for simulation of postoperative alignment are increasingly gaining importance. Tools requiring manual annotations are userdependent and prone to input errors [18]. Machine learning algorithms have been shown to be helpful for predicting alignment [19]. A previously published statistical shape model (SSM) was trained and used to predict improved spinal alignment in patients with spinal disorders [20]. Annotated radiographic data were used to train the SSM, and the training dataset comprised only asymptomatic subjects without spinal pathology or deformity. The trained model contains information about the variation of sagittal spinal alignment within an asymptomatic population. Using patient-specific parameters, a potentially optimal plan for restoration or maintenance of the sagittal spinal balance can be provided.

The present study was performed to investigate differences in spinal alignment between postoperative radiographs after single-level lumbar fusion at L4/5 and the SSM-calculated optimal spinal alignment, comparing patients with and without the development of ASD. We hypothesized that non-conformance to the SSM-calculated patient-specific optimal spinal alignment is associated with the development of ASD.

\section{Materials and methods}

\section{Patient population}

In this case-control study, we retrospectively reviewed all patients after primary spinal fusion surgery, one group were revised for treatment of ASD from 2004 to 2017 and compared them with a control group of patients who did not develop ASD after primary fusion at a single institution. We included patients who primarily underwent single-level fusion at L4/5 using a posterior approach only with pedicle screw instrumentation with or without intervertebral cage placement. In the control group, patients with $<4$ years of follow-up were excluded. In both groups, patients with preoperative or postoperative radiographs of insufficient quality were excluded. All radiographs were calibrated and displayed both femoral heads and all vertebrae from T12 to the sacrum. The preoperative degeneration of the adjacent segment was measured on MRIs with the Pfirrmann [21] and Weishaupt [22] classification.

\section{Statistical shape model}

As previously described, an SSM is used to predict the optimal positions of the vertebral body centers based on spinopelvic landmarks (femoral heads and S1 endplate) [20]. On preoperative lateral radiographs, the sacral endplate and center of the bicoxofemoral axis (determined by the center of each femoral head) were annotated. These patient-specific geometries were used to calculate the predicted physiological position of each center of the vertebral body from T12 to L5. Furthermore, all corners of the vertebral bodies from L5 to T12 were annotated on the preoperative and first postoperative lateral radiographs after single-level fusion. The center of each vertebral body was determined by calculating the mean of all annotated corner points (Fig. 1).

The predicted center of each vertebral body was compared with both the annotated preoperative and postoperative vertebral positions of each patient. This comparison was performed in a two-dimensional plane, and the vertical, horizontal, and total distance was measured. Additionally, the total distance from the preoperative to postoperative position of each vertebral body was evaluated without reference to the SSM-predicted positions.

To correct for the patient's height, the T12 segment was set as given by the patient and was therefore the same height as the given output of the SSM-calculated T12 height.

Because the SSM-predicted vertebral positions were based on the preoperative pelvic configuration, the predicted points were placed on the postoperative radiograph by overlapping the posterior boundary of the S1 endplate (Fig. 1). In this way, the predicted vertebral centers could be compared with both the preoperative and postoperative vertebral positions.

\section{Statistics}

Statistical analysis was performed with IBM SPSS version 25 (IBM Corp., Armonk, NY, USA) and Stata version 13.1 (StataCorp LP, College Station, TX, USA). The distance to the statistical ideal was calculated for every vertebra using the formula for the root mean square error (RMSE). A parametric independent-samples $t$-test was performed for intergroup differences between the distances to the SSM. Data are presented as mean \pm standard deviation. Epifusional classification crosstable was calculated with fisher's exact test. The chi square test was used to compare the interbody fusions. The level of significance in all tests was set at $p<0.05$. 
Fig. 1 Two examples of postoperative spinal alignment versus optimal predicted sagittal alignment. Left: Case in ASD group. Right: Case in control group. For prediction of the optimal sagittal alignment, the spinopelvic landmarks (centers of the femoral heads and the sacral endplate) were annotated. The statistical shape model then calculated the optimal vertebral centers (blue circles) based on the spinopelvic annotations. The true vertebral centers (red circles) are the intersections of the annotated anterosuperior, posterosuperior, anteroinferior, and posteroinferior aspects of each vertebral body. ASD, adjacent segment disease; postop, postoperative

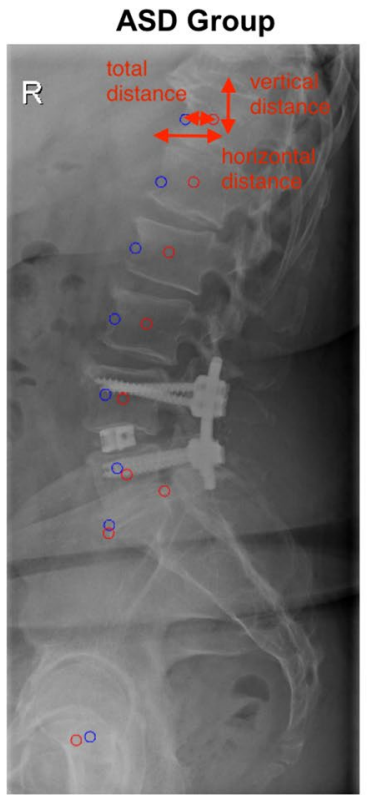

o: postop vertebral centers

o: predicted vertebral centers using statistical model

\section{RESULTS}

\section{Patient population}

In total, 330 consecutive patients were screened for the ASD group. Of these, 22 patients were eligible for inclusion. Patients were excluded for fusion at levels other than L4/5 ( $n=247)$; a complex medical history, incomplete medical records, or prior lumbar spine surgery $(n=21)$; or radiographs of insufficient quality or missing information about pixel dimensions $(n=40)$.

In total, 576 patients were screened for the control group, and 25 were included. Patients were excluded because of a follow-up of $<4$ years $(n=186)$, previous operations $(n=91)$, recurrent pain or other surgery-related issues $(n=222)$, or radiographs of insufficient quality or missing segmenting of the pixels on the scan $(n=52)$.

The patient demographics were not significantly different between the groups with the exception of age at the primary surgery, which was lower in the control group $(60 \pm 12.0$ years $)$ than in the ASD group $(66 \pm 7.8$ years, $p=0.043$ ) (Table 1). There was no significant difference in body mass index or sex. There was also no significant difference in interbody fusion with an intervertebral cage between the control and ASD group (15 (60.0\%) vs. 16 $(72.2 \%)$ patients, respectively; $p=0.358)$. Most importantly there was no difference in preoperative degeneration of the adjacent segment between the groups (Pfirrmann $p=0.458$, Weishaupt $p=0.212$ ) (Table 2). The MRIs were taken 1.6 months $( \pm 1.9)$ before the operation. Fourtyfive (96\%) MRIs where analyzed, two (4\%) were not available for review.
Table 1 Patient characteristics

\begin{tabular}{llll}
\hline Variable & ASD & Control & $P$ value \\
\hline Patients, $n$ & 22 & 25 & \\
Age, years & $66 \pm 7.8$ & $60 \pm 12.0$ & $\mathbf{0 . 0 4 3}$ \\
Female sex, $\%$ & 68.0 & 68.2 & \\
BMI, kg/m ${ }^{2}$ & $25.2 \pm 4.2$ & $26.9 \pm 5.3$ & 0.237 \\
Interbody fusion, $\%$ & 72.2 & 60.0 & 0.369 \\
\hline
\end{tabular}

Data are given as mean \pm standard deviation unless otherwise indicated. Boldface type indicates statistical significance

$A S D$ Adjacent segment disease, BMI Body mass index

Table 2 Preoperative epifusional degeneration L3/4

\begin{tabular}{llllll}
\hline Grade & \multicolumn{2}{l}{ Pfirrmann } & & & Weishaupt \\
\cline { 6 - 6 } \cline { 5 - 6 } & ASD & CTRL & & ASD & CTRL \\
\hline 0 & & & 1 & 0 \\
I & 0 & 0 & 9 & 13 \\
II & 1 & 3 & 12 & 8 \\
III & 12 & 8 & & 0 & 2 \\
IV & 5 & 5 & & \\
V & 4 & 7 & & \\
\hline
\end{tabular}

Quantification of the patients epifusional segment degeneration according to Pfirrmann and Weisshaupt at the point of the operation ASD Adjacent segment disease, CTRL Control group

\section{Spinal alignment}

All spinopelvic parameters on the postoperative radiographs, the relationship between pelvic incidence and 
lumbar lordosis, as well as the calculated ideal pelvic tilt as described by Vialle et al. [23] and its deviation to our patient population, was not significantly different between the groups (Table 3).

\section{Total distance from predicted optimal spinal alignment}

Preoperatively, the mean distance (RMSE) from the centers of the vertebral bodies to the SSM-predicted ideal position was very similar between the two groups, with no significant difference (Fig. 2). At the L5 level, this distance was $6.7 \pm 3.0 \mathrm{~mm}$ in the control group and $6.0 \pm 2.5 \mathrm{~mm}$ in the ASD group $(p=0.390)$, whereas at the T12 level,

Table 3 Postoperative spinopelvic parameters

\begin{tabular}{lrrrrrr}
\hline Variable & ASD & & & \multicolumn{2}{c}{ Control } & $P$ value \\
\cline { 2 - 3 } & Mean & SD & & Mean & SD & \\
\hline PI & 55.4 & 8.8 & 56.7 & 14.0 & 0.700 \\
PT & 20.5 & 5.8 & & 23.6 & 8.1 & 0.134 \\
SS & 34.9 & 7.3 & & 33.1 & 7.9 & 0.414 \\
LL & 50.8 & 10.7 & & 48.6 & 9.9 & 0.463 \\
$\Delta$ PI-LL & 4.6 & 10.1 & & 8.2 & 9.2 & 0.211 \\
PTi & 13.5 & 3.3 & & 14.0 & 5.2 & 0.700 \\
$\Delta$ PTi-PT & 7.0 & 4.7 & 9.6 & 4.3 & 0.050 \\
\hline
\end{tabular}

$A S D$ Adjacent segment disease, $S D$ Standard deviation, PI Pelvic incidence, $P T$ Pelvic tilt, SS Sacral slope, $L L$ Lumbar lordosis, $\triangle P I-L L$ Pelvic incidence-lumbar lordosis mismatch, $P T i$ ideal pelvic tilt, $\triangle P T i-P T$ Ideal pelvic tilt-pelvic tilt mismatch

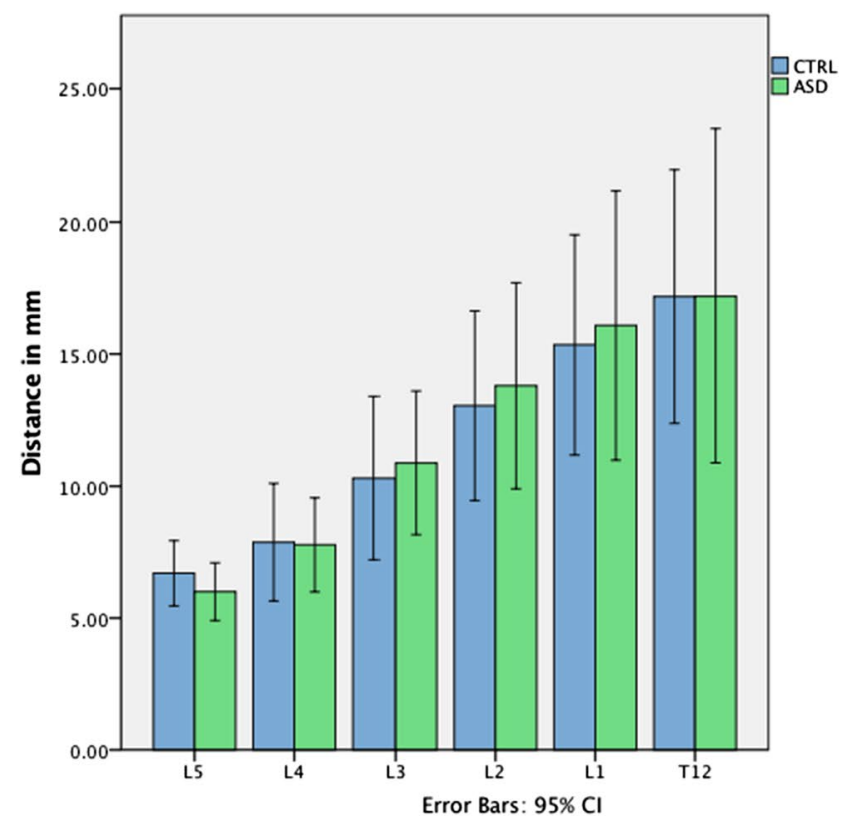

the distance was $17.18 \pm 11.6 \mathrm{~mm}$ in the control group and $17.19 \pm 14.2 \mathrm{~mm}$ in the ASD group $(p=0.998)$. The sum of all total distances from the calculated ideal was $70.5 \pm 40.2 \mathrm{~mm}$ the control group and $71.7 \pm 44.1 \mathrm{~mm}$ in the ASD group $(p=0.918)$.

Postoperatively, the most proximally measured vertebra (T12) had a mean distance of $14.84 \pm 12.9 \mathrm{~mm}$ in the control group and $21.35 \pm 13.0 \mathrm{~mm}$ in the ASD group $(p=0.092)$. The sum of all total distances was $67.71 \pm 46.2 \mathrm{~mm}$ in the control group and $86.81 \pm 34.3 \mathrm{~mm}$ in the ASD group $(p=0.119)$.

\section{Horizontal distance from predicted optimal spinal alignment}

Preoperatively, no significant difference was found between the groups (Fig. 3). For L5, the mean distance postoperatively was $5.48 \pm 3.3 \mathrm{~mm}$ in the control group and $4.57 \pm 2.3 \mathrm{~mm}$ in the ASD group $(p=0.286)$. At the T12 level, the mean distance was $14.84 \pm 12.9 \mathrm{~mm}$ in the control group and $21.35 \pm 13.0 \mathrm{~mm}$ in the ASD group $(p=0.092)$.

\section{Vertical distance from predicted optimal spinal alignment}

Preoperatively, no significant difference was found between the groups (Fig. 4). The greatest distance from the statistical ideal was found at the L4 level in both groups $(4.09 \pm 3.7$ and $4.31 \pm 2.9 \mathrm{~mm}$ in the control and ASD group, respectively; $p=0.823$ ). The decreasing distance toward the cranial segments was due to the vertical referencing to the T12

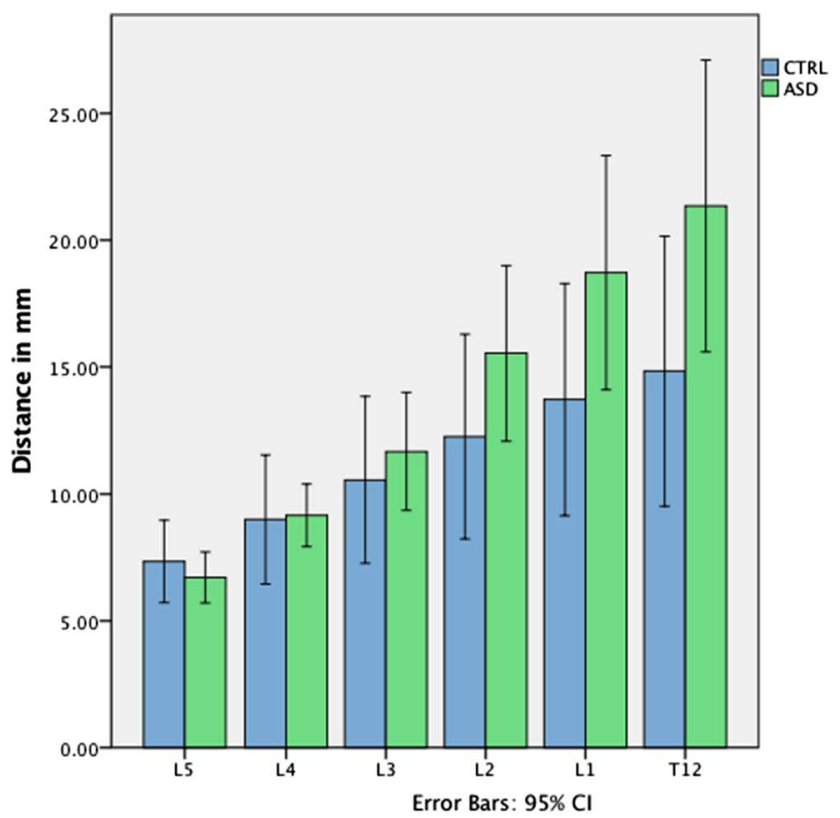

Fig. 2 Total distance to the statistical shape model-calculated ideal in root mean square error. Left: Preoperative. Right: Postoperative. Green bars: ASD group. Blue bars: CTRL group. Error bars: 95\% CIs. CTRL, control; ASD, adjacent segment disease; CI, confidence interval 

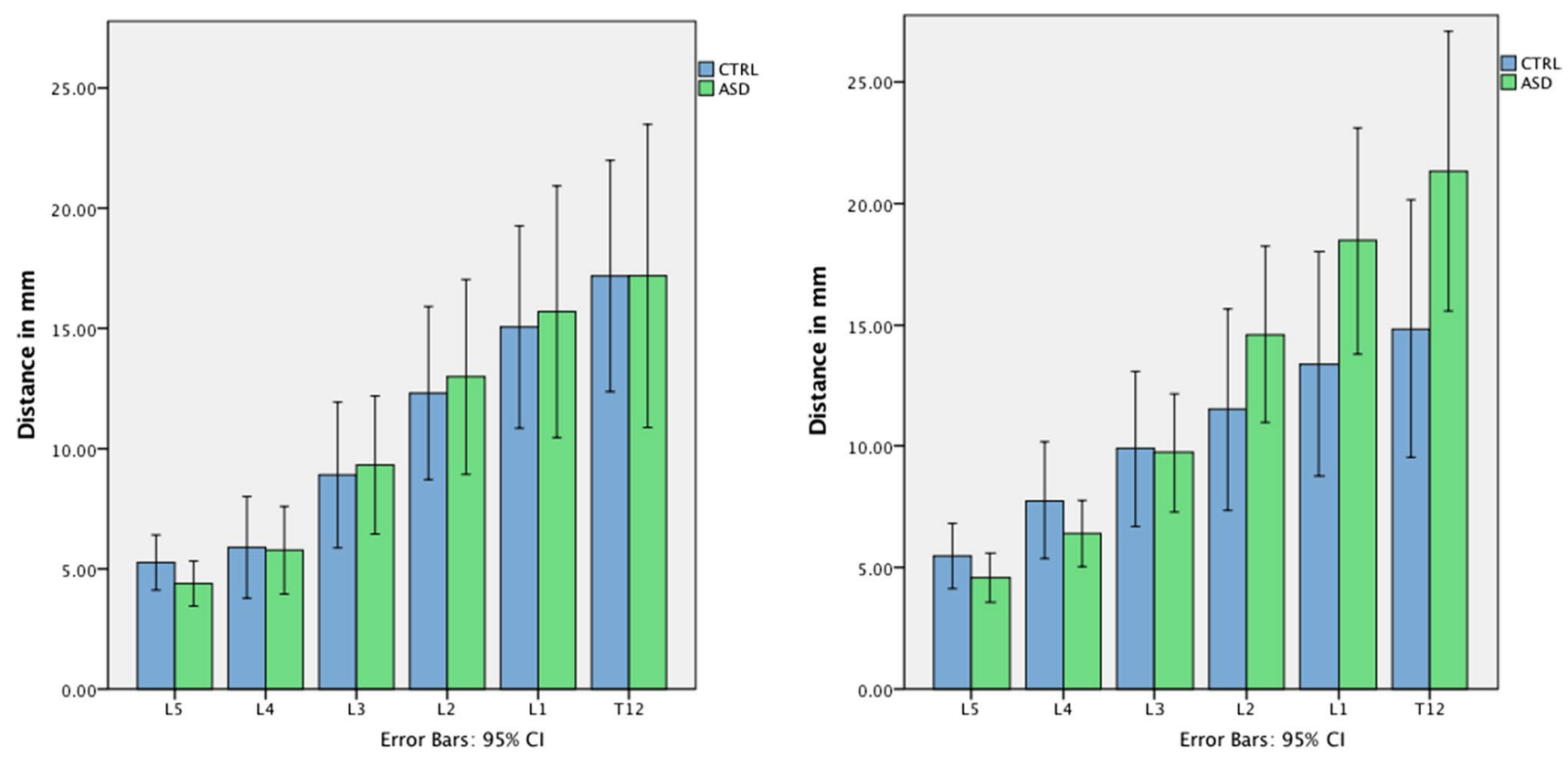

Fig. 3 Horizontal distance to the statistical shape model-calculated ideal in root mean square error. Left: Preoperative. Right: Postoperative. Green bars: ASD group. Blue bars: CTRL group. Error bars: 95\% CIs. CTRL, control; ASD, adjacent segment disease; CI, confidence interval
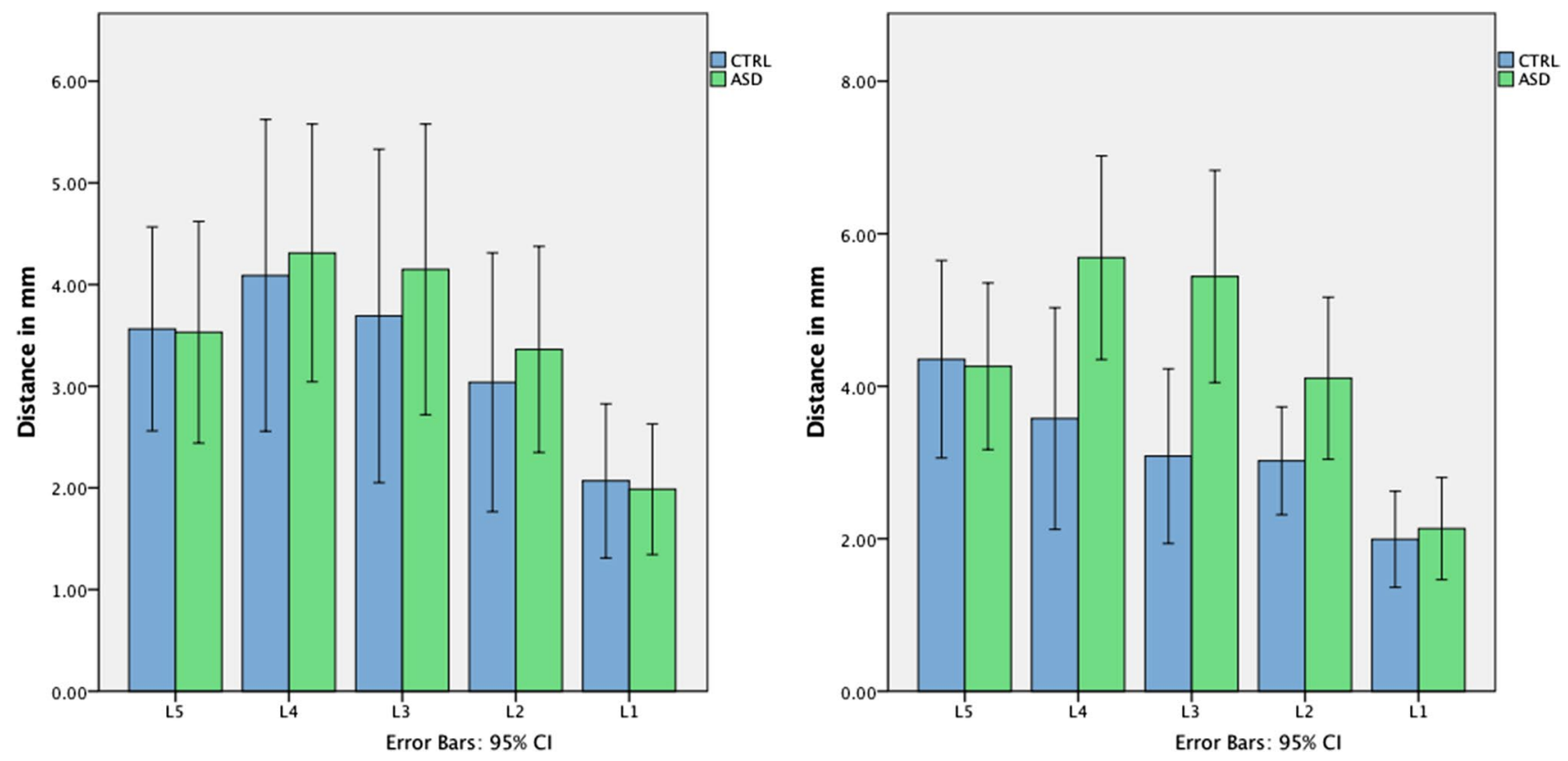

Fig. 4 Vertical distance to the statistical shape model-calculated ideal in root mean square error. Left: Preoperative. Right: Postoperative. Green bars: ASD group. Blue bars: CTRL group. Error bars: 95\% CIs. CTRL, control; ASD, adjacent segment disease; CI, confidence interval

segment, which equalized every patient's height and was therefore used as a reference, as explained above.

Postoperatively, significant differences were observed in the operated L4 and the adjacent L3 vertebrae between the two groups. At the L4 vertebra, the distance from the ideal was $5.69 \pm 3.0 \mathrm{~mm}$ in the ASD group and $3.58 \pm 3.5 \mathrm{~mm}$ in the control group $(p=0.034)$. At the L3 vertebra, this distance was $5.44 \pm 3.13 \mathrm{~mm}$ in the ASD group and $3.08 \pm 2.77 \mathrm{~mm}$ in the control group $(p=0.009)$. 


\section{Changes in preoperative to postoperative position of vertebral bodies}

The distance from the preoperative to postoperative vertebral bodies was greater in the control group than in the ASD group. This trend began at the L4 level and continued through all cranial segments. At the L4 level, the distance was $7.50 \pm 6.4 \mathrm{~mm}$ in the control group and $6.96 \pm 4.50 \mathrm{~mm}$ in the ASD group ( $p=0.742)$ (Fig. 5). This continued through all of the more cranial segments, with the greatest change at the T12 level (distance of $19.7 \pm 19.8 \mathrm{~mm}$ in the control group and $16.8 \pm 11.3 \mathrm{~mm}$ in the ASD group; $p=0.554)$.

\section{Discussion}

As the numbers of primary spinal fusion procedures continuously increase, so do the rates of revision spinal surgery [24-26]. ASD is the most important yet insufficiently controllable long-term complication associated with lumbar spinal fusion. Within 10 years after primary lumbar fusion, $22 \%$ to $36 \%$ of patients require additional decompression and/or proximal extension of the spinal fusion because of ASD [7, 27]. Among other risk factors, unfavorable spinopelvic alignment has been identified as a major driver for the occurrence of ASD in the lumbar spine. It is therefore the surgeon's duty to optimally influence the sagittal balance

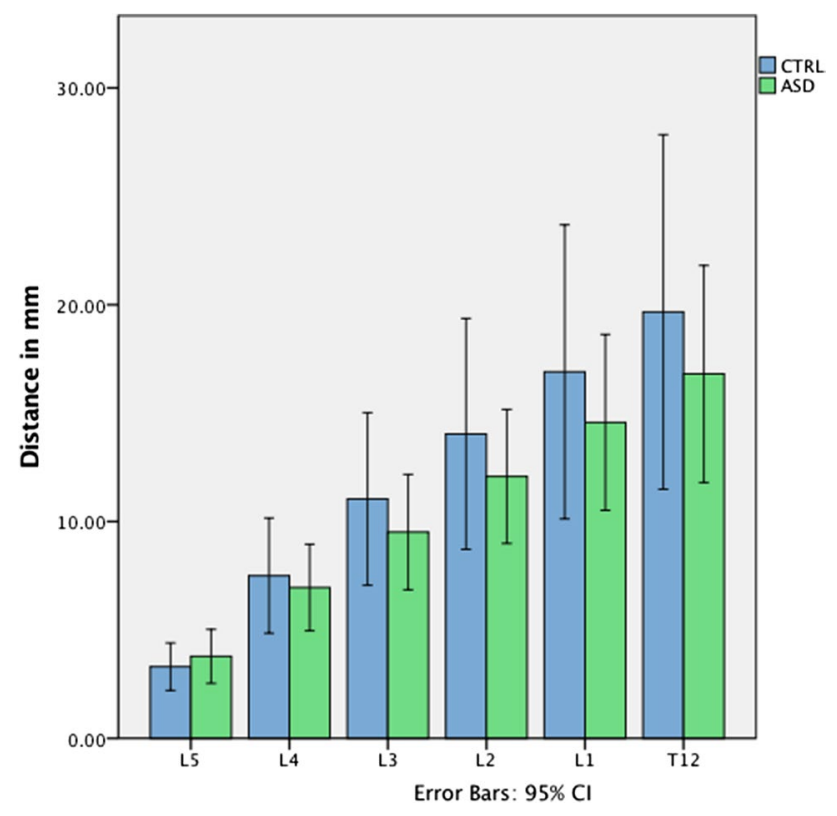

Fig. 5 Change in distance of the vertebral centers from the preoperative to postoperative position. Green bars: ASD group. Blue bars: CTRL group. Error bars: 95\% CIs. CTRL, control; ASD, adjacent segment disease; CI, confidence interval when performing fusion surgery $[28,29]$. The relationship between the physiologic upright posture and the lumbosacral alignment was well described by Legaye et al. [30] and Duval-Beaupère et al. [31]. Boulay et al. [31] further developed a formula to predict lumbar lordosis based on the pelvic incidence and stated that if the standing position is outside the "efficiency zone," adaption of the spine and pelvis is exceeded and causes pathological conditions and loading patterns. Rothenfluh et al. [32] demonstrated that patients with $\Delta$ PI-LL of $>10$ degrees have a tenfold higher risk of developing ASD. However, although the definition of optimal alignment for spinal fusion surgery follows geometrical criteria, it strongly relies on the surgeon's subjective decisions.

Because the spinopelvic system is a highly complex construct and not yet fully understood, statistical models have been introduced to simulate physiological alignments and ameliorate preoperative planning. The SSM used in the present study was developed by Caprara et al. [20]. The SSM was initially trained with 60 annotated radiographs of asymptomatic healthy subjects and calculates the optimal position of each vertebral body based on spinopelvic landmarks. In contrast to more common spinopelvic parameters, such as the $\Delta$ PI-LL and sagittal vertical axis, the SSM predicts the patient-specific optimal position of each vertebra. This may be especially helpful in lower back fusion constructs because the lowest two segments are in charge of the major part of the lordosis.

The present retrospective study compared the spinal alignment evaluated by the patient-specific SSM calculation of patients with ASD versus an asymptomatic cohort of patients before and immediately after single-level fusion at $\mathrm{L} 4 / 5$. We found greater misalignment in patients with ASD than in the asymptomatic control group, which confirms the accuracy of the SSM in clinical situations. Preoperatively, a homogenous and similar distribution of spinal alignments around the calculated ideals was found in all patients. In contrast, greater misalignment was seen in all directions (horizontal, vertical, and total distance) on standing postoperative radiographs in the ASD group than in the controls. These differences in the horizontal and total distance were more prominent in the more cranial segments. This greater deviation in the cranial segments is likely related to the increased uncertainty of the SSM towards cranial as described in Caprara et al. [20] and was attributed to the increasing distance from the input pelvic configuration. However, the cranial segments deviated more from the SSM ideal in the ASD group than in the controls. Because the postoperative radiograph is taken within the first few postoperative days and long before the occurrence of ASD, the differences from the SSM ideal may indicate the long-term progression immediately after surgery. In fact, there was no statistical significant difference in the preoperative degeneration of the adjacent 
segment in both groups according to the classification of Pfirrmann [21] und Weishaupt [22].

Interestingly, a greater change in preoperative to postoperative alignment was seen in the control group than ASD group (Fig. 4). Because the fusion was at the L4/5 level, these segments were mainly influenced intraoperatively. A greater change to the L4 segment was seen in the control group than ASD group, which further influenced the cranial segments. We interpret this as an intraoperative change, which is crucial because the segments from L4 to $\mathrm{S} 1$ are responsible for $66 \%$ of the total lumbar lordosis [33]. Therefore, surgeries involving the lower lumbar spine have a tremendous effect on the total spinal alignment, the development of ASD, and the patient's quality of life.

Better alignment in the control group was also found in view of the vertical distance to the ideal. Because the SSM is trained with young individuals, the deviation of the L5 vertebra in the vertical direction to the mean is partly due to degeneration of the L5/S1 segment and partly due to the individual patient's shape [20]. However, significantly better postoperative height restoration was seen in the control group than in the ASD group. Height restoration of the fused level is an important factor associated with the occurrence of ASD [34] and is another corresponding factor with the here found results.

The postoperative spinopelvic parameters as well as the preoperative degeneration of the epifusional segment showed no significant difference. As mentioned above, even the $\Delta$ PI-LL as one of the major biomechanical risk factors was the same in both groups. This indicates that the SSM might be an additional tool, in conjunction with the established indexes, for preoperative planning.

This study confirms the hypothesis that patients who develop ASD show greater non-conformance in spinal alignment to the SSM-calculated ideal than do controls on the first postoperative radiographs. However, comparative trials with large sample sizes are needed to clarify the accuracy of patient-specific simulation of the spinal alignment using the SSM.

This study has limitations. The sample sizes of the two cohorts included in this study were small, thereby limiting its statistical power. The SSM's training population was initially constituted by rather young subjects and does not address variances in age, sex, or race. Thus, the SSM remains a rough estimation of the ideal spinal alignment. The authors are aware of the physiological spinal degeneration with age. The degenerated spine is in our understanding not the ideal spinal alignment for the individual patient, and therefore, our statistical ideal is trained with a young and healthy population. But to better individualize the patientspecific simulations we could think of an SSM that addresses not only the patient's individual spinopelvic anatomy, but also the body habitus. Further technical limitations of the
SSM were described in detail in the original publication [20]. The authors would like to point out that SSM should not be understood as a more effective tool compared to the already known indexes but might be an interesting additional point of view that warrants further research.

\section{Conclusion}

Patients who develop ASD requiring revision after lumbar spinal fusion have greater differences from the SSM-calculated optimal spinal sagittal alignment on the first postoperative radiographs. Further research might help to understand the value of SSM, in conjunction with already established indexes, for the preoperative planning of optimal spinal alignment.

Acknowledgements This work is part of the SURGENT project under the umbrella of University Medicine Zurich / Hochschulmedizin Zürich. The authors also thank Angela Morben, DVM, ELS, from Edanz Group (https://en-author-services.edanzgroup.com/), for editing a draft of this manuscript.

Funding Open Access funding provided by Universität Zürich.

\section{Declarations}

Conflict of interests The authors declare that they have no conflict of intereset.

Ethical approval All procedures performed in studies involving human participants were in accordance with the ethical standards of the institutional and national research committee and with the 1964 Declaration of HELSINKI and its later amendments or comparable ethical standards. Informed consent was obtained from all individual participants included in the study.

Open Access This article is licensed under a Creative Commons Attribution 4.0 International License, which permits use, sharing, adaptation, distribution and reproduction in any medium or format, as long as you give appropriate credit to the original author(s) and the source, provide a link to the Creative Commons licence, and indicate if changes were made. The images or other third party material in this article are included in the article's Creative Commons licence, unless indicated otherwise in a credit line to the material. If material is not included in the article's Creative Commons licence and your intended use is not permitted by statutory regulation or exceeds the permitted use, you will need to obtain permission directly from the copyright holder. To view a copy of this licence, visit http://creativecommons.org/licenses/by/4.0/.

\section{References}

1. Boos N, Webb JK (1997) Pedicle screw fixation in spinal disorders: a European view. Eur Spine J: official Publ Eur Spine Soc, Eur Spinal Deform Soc, Eur Section Cerv Spine Res Soc 6:2-18. https://doi.org/10.1007/bf01676569 
2. Rajaee SS, Bae HW, Kanim LE, Delamarter RB (2012) Spinal fusion in the United States: analysis of trends from 1998 to 2008. Spine 37:67-76. https://doi.org/10.1097/BRS.0b013e31820cccfb

3. Axelsson P, Johnsson R, Stromqvist B (1997) The spondylolytic vertebra and its adjacent segment. Mobility measured before and after posterolateral fusion. Spine 22:414-417. https://doi.org/10. 1097/00007632-199702150-00012

4. Chen WJ, Lai PL, Niu CC, Chen LH, Fu TS, Wong CB (2001) Surgical treatment of adjacent instability after lumbar spine fusion. Spine 26:E519-524. https://doi.org/10.1097/00007632200111150-00024

5. Weinhoffer SL, Guyer RD, Herbert M, Griffith SL (1995) Intradiscal pressure measurements above an instrumented fusion. A Cadaveric Study Spine 20:526-531. https://doi.org/10.1097/00007 632-199503010-00004

6. Park P, Garton HJ, Gala VC, Hoff JT, McGillicuddy JE (2004) Adjacent segment disease after lumbar or lumbosacral fusion: review of the literature. Spine 29:1938-1944. https://doi.org/ 10.1097/01.brs.0000137069.88904.03

7. Sears WR, Sergides IG, Kazemi N, Smith M, White GJ, Osburg B (2011) Incidence and prevalence of surgery at segments adjacent to a previous posterior lumbar arthrodesis. The Spine J: Off J North Am Spine Soc 11:11-20. https://doi.org/10.1016/j. spinee.2010.09.026

8. Liang J, Dong Y, Zhao H (2014) Risk factors for predicting symptomatic adjacent segment degeneration requiring surgery in patients after posterior lumbar fusion. J Orthop Surg Res 9:97. https://doi.org/10.1186/s13018-014-0097-0

9. Lee CS, Hwang CJ, Lee SW, Ahn YJ, Kim YT, Lee DH, Lee MY (2009) Risk factors for adjacent segment disease after lumbar fusion. European Spine J : Off Publ Eur Spine Soc, the Eur Spinal Deform Soc, and the Eur Section the Cerv Spine Res Soc 18:1637-1643. https://doi.org/10.1007/s00586-009-1060-3

10. Ou CY, Lee TC, Lee TH, Huang YH (2015) Impact of body mass index on adjacent segment disease after lumbar fusion for degenerative spine disease. Neurosurgery. https://doi.org/ 10.1227/neu.0000000000000627

11. Umehara S, Zindrick MR, Patwardhan AG, Havey RM, Vrbos LA, Knight GW, Miyano S, Kirincic M, Kaneda K, Lorenz MA (2000) The biomechanical effect of postoperative hypolordosis in instrumented lumbar fusion on instrumented and adjacent spinal segments. Spine 25:1617-1624. https://doi.org/10.1097/ 00007632-200007010-00004

12. Schwab FJ, Blondel B, Bess S, Hostin R, Shaffrey CI, Smith JS, Boachie-Adjei O, Burton DC, Akbarnia BA, Mundis GM, Ames CP, Kebaish K, Hart RA, Farcy JP, Lafage V (2013) Radiographical spinopelvic parameters and disability in the setting of adult spinal deformity: a prospective multicenter analysis. Spine 38:E803-812. https://doi.org/10.1097/BRS.0b013e3182 $92 \mathrm{~b} 7 \mathrm{~b} 9$

13. Lafage V, Schwab F, Patel A, Hawkinson N, Farcy JP (2009) Pelvic tilt and truncal inclination: two key radiographic parameters in the setting of adults with spinal deformity. Spine 34:E599-606. https://doi.org/10.1097/BRS.0b013e3181aad219

14. Glassman SD, Bridwell K, Dimar JR, Horton W, Berven S, Schwab F (2005) The impact of positive sagittal balance in adult spinal deformity. Spine 30:2024-2029. https://doi.org/10.1097/ 01.brs.0000179086.30449.96

15. Radcliff KE, Kepler CK, Jakoi A, Sidhu GS, Rihn J, Vaccaro AR, Albert TJ, Hilibrand AS (2013) Adjacent segment disease in the lumbar spine following different treatment interventions. The Spine J: Off J of the North Am Spine Soc 13:1339-1349. https:// doi.org/10.1016/j.spinee.2013.03.020

16. Phan K, Nazareth A, Hussain AK, Dmytriw AA, Nambiar M, Nguyen D, Kerferd J, Phan S, Sutterlin C 3rd, Cho SK, Mobbs RJ (2018) Relationship between sagittal balance and adjacent segment disease in surgical treatment of degenerative lumbar spine disease: meta-analysis and implications for choice of fusion technique. Eur Spine J Off Publ of the Eur Spine Soc, The Eur Spinal Deform Soc, and the Eur Section of the Cerv Spine Res Soc 27:1981-1991. https://doi.org/10.1007/s00586-018-5629-6

17. Kumar MN, Baklanov A, Chopin D (2001) Correlation between sagittal plane changes and adjacent segment degeneration following lumbar spine fusion. Eur Spine J: Off Publ of the Eur Spine Soc, the Eur Spinal Deform Soc, and the Eur Section of the Cerv Spine Res Soci 10:314-319. https://doi.org/10.1007/s005860000 239

18. Smith JS, Bess S, Shaffrey CI, Burton DC, Hart RA, Hostin R, Klineberg E (2012) Dynamic changes of the pelvis and spine are key to predicting postoperative sagittal alignment after pedicle subtraction osteotomy: a critical analysis of preoperative planning techniques. Spine 37:845-853. https://doi.org/10.1097/BRS. 0b013e31823b0892

19. Lafage R, Pesenti S, Lafage V, Schwab FJ (2018) Self-learning computers for surgical planning and prediction of postoperative alignment. Eur Spine J: Off Publ of the Eur Spine Soc, The Eur Spinal Deform Soc, and the Eur Section of the Cerv Spine Res Soc 27:123-128. https://doi.org/10.1007/s00586-018-5497-0

20. Caprara S, Moschini G, Snedeker JG, Farshad M, Senteler M (2020) Spinal sagittal alignment goals based on statistical modelling and musculoskeletal simulations. J Biomech 102:109621. https://doi.org/10.1016/j.jbiomech.2020.109621

21. Pfirrmann CW, Metzdorf A, Zanetti M, Hodler J, Boos N (2001) Magnetic resonance classification of lumbar intervertebral disc degeneration. Spine 26:1873-1878

22. Weishaupt D, Zanetti M, Boos N, Hodler J (1999) MR imaging and CT in osteoarthritis of the lumbar facet joints. Skeletal Radiol 28:215-219. https://doi.org/10.1007/s002560050503

23. Vialle R, Levassor N, Rillardon L, Templier A, Skalli W, Guigui $P(2005)$ Radiographic analysis of the sagittal alignment and balance of the spine in asymptomatic subjects. J Bone Joint Surg Am 87:260-267. https://doi.org/10.2106/JBJS.D.02043

24. Mok JM, Cloyd JM, Bradford DS, Hu SS, Deviren V, Smith JA, Tay B, Berven SH (2009) Reoperation after primary fusion for adult spinal deformity: rate, reason, and timing. Spine 34:832839. https://doi.org/10.1097/BRS.0b013e31819f2080

25. Pichelmann MA, Lenke LG, Bridwell KH, Good CR, O'Leary PT, Sides BA (2010) Revision rates following primary adult spinal deformity surgery: six hundred forty-three consecutive patients followed-up to twenty-two years postoperative. Spine 35:219-226. https://doi.org/10.1097/BRS.0b013e3181c91180

26. Zhu F, Bao H, Liu Z, Bentley M, Zhu Z, Ding Y, Qiu Y (2014) Unanticipated revision surgery in adult spinal deformity: an experience with 815 cases at one institution. Spine 39:B36-44. https:// doi.org/10.1097/brs.0000000000000463

27. Ghiselli G, Wang JC, Bhatia NN, Hsu WK, Dawson EG (2004) Adjacent segment degeneration in the lumbar spine. J Bone Jt Surg Am 86:1497-1503. https://doi.org/10.2106/00004623-20040 7000-00020

28. Schwab F, Patel A, Ungar B, Farcy JP, Lafage V (2010) Adult spinal deformity-postoperative standing imbalance: how much can you tolerate? An overview of key parameters in assessing alignment and planning corrective surgery. Spine 35:2224-2231. https://doi.org/10.1097/BRS.0b013e3181 ee6bd4

29. Glassman SD, Berven S, Bridwell K, Horton W, Dimar JR (2005) Correlation of radiographic parameters and clinical symptoms in adult scoliosis. Spine 30:682-688. https://doi.org/10.1097/01.brs. 0000155425.04536.f7

30. Legaye J, Duval-Beaupere G, Hecquet J, Marty C (1998) Pelvic incidence: a fundamental pelvic parameter for three-dimensional regulation of spinal sagittal curves. Eur Spine J: Off Publ of the Eur Spine Soc, the Eur Spinal Deform Soc, and the Eur Section of 
the Cerv Spine Res Soc 7:99-103. https://doi.org/10.1007/s0058 60050038

31. Boulay C, Tardieu C, Hecquet J, Benaim C, Mouilleseaux B, Marty C, Prat-Pradal D, Legaye J, Duval-Beaupere G, Pelissier J (2006) Sagittal alignment of spine and pelvis regulated by pelvic incidence: standard values and prediction of lordosis. Eur Spine J: Off Publ of the Eur Spine Soc, the Eur Spinal Deform Soc, and the Eur Section of the Cerv Spine Res Soc 15:415-422. https:// doi.org/10.1007/s00586-005-0984-5

32. Rothenfluh DA, Mueller DA, Rothenfluh E, Min K (2015) Pelvic incidence-lumbar lordosis mismatch predisposes to adjacent segment disease after lumbar spinal fusion. Eur Spine J: Off Publ of the Eur Spine Soc, the Eur Spinal Deform Soc, and the Eur Section of the Cerv Spine Res Soc 24:1251-1258. https://doi.org/10. 1007/s00586-014-3454-0

33. Roussouly P, Pinheiro-Franco JL (2011) Sagittal parameters of the spine: biomechanical approach. Eur Spine J: Off Publ of the
Eur Spine Soc, the Eur Spinal Deform Soc, and the Eur Section of the Cerv Spine Res Soc 20(Suppl 5):578-585. https://doi.org/ 10.1007/s00586-011-1924-1

34. Tian H, Wu A, Guo M, Zhang K, Chen C, Li X, Cheng X, Zhou T, Murray SS, Sun X, Zhao J (2018) Adequate restoration of disc height and segmental lordosis by lumbar interbody fusion decreases adjacent segment degeneration. World Neurosurg 118:e856-e864. https://doi.org/10.1016/j.wneu.2018.07.075

Publisher's Note Springer Nature remains neutral with regard to jurisdictional claims in published maps and institutional affiliations. 